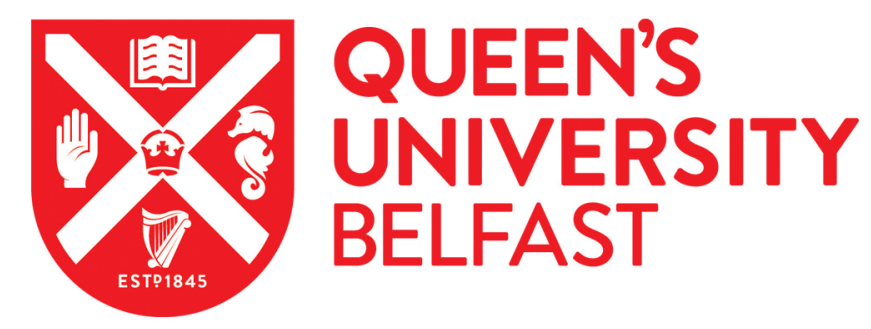

\title{
Knowledge and Power Relations in Older Patients' Communication about Medications across Transitions of Care
}

Ozavci, G., Bucknall, T., Woodward-Kron, R., Hughes, C., Jorm, C., Joseph, K., \& Manias, E. (2021).

Knowledge and Power Relations in Older Patients' Communication about Medications across Transitions of Care. Qualitative Health Research, 31(14), 2678-2691. https://doi.org/10.1177/10497323211043494

Published in:

Qualitative Health Research

Document Version:

Peer reviewed version

Queen's University Belfast - Research Portal:

Link to publication record in Queen's University Belfast Research Portal

Publisher rights

Copyright 2021, the Authors.

This work is made available online in accordance with the publisher's policies. Please refer to any applicable terms of use of the publisher

\section{General rights}

Copyright for the publications made accessible via the Queen's University Belfast Research Portal is retained by the author(s) and / or other copyright owners and it is a condition of accessing these publications that users recognise and abide by the legal requirements associated with these rights.

Take down policy

The Research Portal is Queen's institutional repository that provides access to Queen's research output. Every effort has been made to ensure that content in the Research Portal does not infringe any person's rights, or applicable UK laws. If you discover content in the Research Portal that you believe breaches copyright or violates any law, please contact openaccess@qub.ac.uk. 
Knowledge and Power Relations in Older Patients' Communication about Medications across Transitions of Care

\section{Abstract}

Communicating about medications across transitions of care is a challenging process for older patients. In this article, we examined communication processes between older patients, family members and health professionals about managing medications across transitions of care, focusing on older patients' experiences. A focused ethnographic design was employed across two metropolitan hospitals. Data collection methods included interviews, observations and focus groups. Following thematic analysis, data were analysed using Fairclough's Critical Discourse Analysis and Medication Communication Model. Older patients' medication knowledge and family members' advocacy challenged unequal power relations between clinicians and patients and families. Doctors' use of authoritative discourse impeded older patients' participation in the medication communication. Older patients perceived that nurses' involvement in medication communication was limited due to their task related routines. To reduce the unequal power relations, health professionals should be more proactive in sharing information about medications with older patients across transitions of care.

Keywords: Communication, medication management, patient medication knowledge, power relations, older patients, transitions of care, patient experiences, patient perspectives, critical discourse analysis. 


\section{Introduction}

Communication about medications is a complex process when older patients move across transitions of care, which can compromise patients' safety when they move between different care settings (Coleman, 2003). Since older patients are likely to have multiple chronic conditions and to be prescribed multiple medications, they may experience medication incidents as they move across settings. These incidents include incorrect techniques of administration, under-dose or overdose of medications, taking unnecessary medications or not adhering to the required treatment (Surbhi et al., 2016). Transitions of care is defined as patients' movements between various locations including hospitals, post-acute and sub-acute nursing facilities, long-term facilities, specialty care offices, patients' homes and also their movements between various health professionals (World Health Organization, 2016). The World Health Organization (WHO) states medication incidents are common across transitions of care due to communication breakdown between health professionals, older patients and family members during ward rounds, hospital admission, discharge communication and bedside consultations (World Health Organization, 2016). For the purpose of this paper, communication about medication refers to interactions between older patients, their families and health professionals through verbal, non-verbal, electronic and written means (Ozavci et al., 2020).

The literature has highlighted that effective communication with older patients during care transitions entails encouraging patients to actively participate in the interactions, to consider communication challenges and the most suitable time to discuss discharge medications, and to provide clear, complete and simplified information about medication changes during hospitalisation (Burbach et al., 2016; Rashidian et al., 2008; Stange et al., 2013). Communication challenges impeding effective medication interactions involved patient 
factors (cognitive impairment, memory loss, language barriers, immediate health status), health professional factors (professionals' role perceptions, multitasking, lack of interdisciplinary communication) or environmental influences (time pressures, distractions, hierarchical and physical structure of the ward) (Allen et al., 2016; Australian Commission on Safety and Quality in Health Care, 2015; Byrne et al., 2011; Macdonald et al., 2014). Past work surrounding medication communication across transitions of care showed that knowledge about effective communication was not translated into practice, which contributed to medication mismanagement and incidents when older patients were transferred between hospital and community settings, particularly following discharge (Bucknall et al., 2019; Manias et al., 2016; Mesteig et al., 2010; Ozavci et al., 2020; Wong \& Hogan, 2016).

Research relating to communication about medication management across transitions of care has been mainly dominated by health professionals' discourses (Chiu et al., 2018; Liu et al., 2014; Shen et al., 2006). There is scant literature on the perspectives of varied voices of older patients or the contributions they can make to communication about their medications. Older patients' disinclination to speak up for themselves during medication communication may be also linked to their perceptions of institutional asymmetry between themselves and health professionals in the hospital environment. Institutional asymmetries provide health professionals with privileged positions in having the autonomy in decision-making processes and control of the amount of knowledge shared with patients (Fairclough, 1992). Research showed that older patients who choose to be silent in decision-making processes reportedly were not confident with their own medication knowledge; therefore, they tended to trust health professionals' medication knowledge and complied with the instructions without questioning on admission and discharge (Bagge et al., 2014). In addition, there were older patients who reported their dissatisfaction with knowledge obtained from health professionals about medication changes during hospitalisations, which negatively influenced their participation in 
the decision-making process across transitions of care (Clyne et al., 2017; Modig et al., 2012). While previous studies emphasised older patients' silences in communication exchange (Moen et al., 2009; Spinewine et al., 2005), there can be situations where older patients are motivated to voice their opinions and involve themselves in medication decision-making processes. Yet, little is known about the dynamics of medication communication between older patients and doctors, nurses and pharmacists in the context of care transitions. Therefore, our research questions were: What are the communication processes between older patients, family members and health professionals about managing medications across transitions of care? What are the opportunities that older people can contribute to communicating about medications across transition points of care? What are the sociocultural and environmental influences that shape older patients' involvement in the medication communication?

\section{Methods}

\section{Design}

A focused ethnographic study was employed for this study. This approach involves addressing a specific social phenomenon comprising common behaviours, shared experiences and perspectives with specific groups (Knoblauch, 2005; Kramlich et al., 2018; Toubøl et al., 2020). The specific social phenomenon of this study comprised older patients' perspectives on communication about medications across transitions of care.

\section{Theoretical Framework}

The theoretical framework adopted for this study was Critical Discourse Analysis (CDA) developed by Norman Fairclough (Fairclough, 1992). According to Fairclough (1992), discourse is a form of social practice, and involves the ways in which language, through talk and text, is represented in the world. Fairclough argues that a dialectical relationship exists 
between discourse and social structure, where discourse shapes or is shaped by social structures such as social relations, systems of knowledge, ideologies, identities, shared ideas and beliefs (Fairclough, 1992).

According to Fairclough (1989), there is a relationship between power in discourse and power behind discourse. Power in discourse means that discourse is considered as a place where power is exercised and occurs in various ways, such as in face-to-face conversations where participants have unequal standing in having opportunities to speak. Power behind discourse addresses how particular types of discourse produced by individuals are shaped by power. Unequal power relations can occur in hierarchical, ideological, legal or political arenas (Fairclough, 1989). Fairclough claims that power is derived from knowledge, and also power generates knowledge. Discursive practices of people are shaped in a way that they are often not aware of power relations surrounding them (Fairclough, 1989).

\section{Research Sites}

The study was conducted across two metropolitan hospital sites, which were under the same tertiary health service in Melbourne, Australia. The first site was a public teaching hospital, which had a capacity of 638 beds. At the first site comprising an acute quaternary referral hospital, research was undertaken at two medical speciality wards and one general medical ward. The second site was a geriatric rehabilitation hospital where the research was conducted at two rehabilitation wards and three aged care wards. This hospital had a capacity of 200 beds, which provided services including domiciliary care, geriatric assessment, psychiatric and rehabilitation care.

\section{Participants}


Inclusion criteria included individuals aged 65 years or older who were admitted to the study wards under investigation. Patients with severe dementia were excluded because the cognitive capacity may impact them to provide informed consent. During observations, older patients with mild or moderate cognitive impairment were included if they were able to verbally consent and their family members were present during the consent process. Inclusion criteria for health professionals were registered nurses, doctors or pharmacists who were employed at least one day a week in the study wards. Inclusion criteria for family members were any individuals who had an older person for whom they care about, situated in hospital, and who could communicate in English. Purposive sampling occurred by seeking out older patients from diverse ages, medical conditions, language backgrounds, and location in different clinical settings. Potential older patient participants were identified by initially scanning patient lists before visiting the ward settings and then collaborating with nurse unit managers or the nurse in charge to confirm older patients' eligibility to participate. Recruitment of patients occurred at the patient bedside of each unit after researchers provided information by verbal communication and participant information sheets. Health professionals were recruited purposively in accordance with their professional disciplines, levels of expertise and length of professional experience within the different clinical settings.

\section{Data Collection}

Data collection comprised semi-structured interviews, participant observations and reflexive focus groups and individual interviews. Observation and interview schedules were trialled from previous research, examining the management of medications across transitions of care in general populations and these schedules were amended to examine key issues for older patients. Researchers, Guncag Ozavci and Kathryn Joseph from pharmacy and nursing backgrounds collected data respectively and were involved in analysing data. Other research 
team members were from nursing, pharmacy, medical, health sociology and health communication backgrounds.

Initially, the researchers conducted semi-structured interviews with older patients. The researchers followed an interview schedule and used additional probing questions to steer discussion. Face-to-face, individual interviews were conducted at the bedside. Older patients were asked to provide their impressions of the medication communication they experienced, and to describe how communication processes affected them, as they moved from one environment to another. An approximate length of an interview was 20 minutes. Examples of questions included: "What things do you think are important to discuss about your medications when you come into hospital or when you are about to leave the hospital? How involved did you feel about decisions made regarding changes to your medications when you first came into hospital? How have health professionals talked to you about your medications while you have been in hospital?"

After completion of the interviews, researchers conducted observations. Observations involved examining older patients' participation in communication activities about medications with health professionals in the context of what individuals were doing and saying, the location of where the communication occurred, and identification of who was present during the communication encounter about medications. Factors that may have had negative impacts on older patients' involvement, such as health professionals' movements at the bedside or workarounds in their practices, were also noted. Data from observations were collected as audio recordings and written field notes and observations were summarised reflectively in electronic format immediately after each observation.

Finally, reflexive focus groups or individual interviews were conducted after completion of the interviews and observations with different older patients and family 
members. The research team formulated open-ended focus group questions after exploring key patterns based on preliminary thematic analysis of interview and observational data. Focus groups were organised as face-to-face sessions with older patients and one or two family members at the bedside. When the family members were not available, individual interviews were conducted with older patients. The researcher facilitating the focus groups ensured that each participant contributed to the focus group session. These sessions were reflexive in nature, whereby quotations from previous interviews with older patients or health professionals or short excerpts from observations were presented to support the particular questions asked during focus groups. Family members participating in focus groups consisted of older patients' spouses $(n=9)$ or children $(n=4)$. To ensure confidentiality, pseudonyms were used instead of real names when the excerpts were presented to participants and in reporting findings.

Data from interviews and focus groups were collected as audio recordings and were transcribed by a professional transcription service, whereas data from observations were transcribed by the researchers themselves.

\section{Data Analysis}

Verbatim transcriptions were undertaken of digital audio recordings. Researchers also analysed handwritten field notes to assess non-verbal cues such as body gestures and movements of the health professionals. Data were imported into NVivo 12 (QRS International) for data management and analysis. All authors independently interpreted the research data. As an initial stage, the research team conducted a thematic analysis of all transcripts using Braun and Clarke (2006), which helped to identify recurring ideas and preliminary codes inductively. After the completion of the thematic analysis, the research team undertook Fairclough's Critical Discourse Analysis (CDA) that enabled comprehensive assessment of the dominant and subordinate discourses in the wider social and cultural structures of the hospital settings. 
The Medication Communication Model was used to provide a conceptual lens for data analysis and it helped to determine discourses pertaining to communication about medication relating to antecedents, communication encounters and consequences. An analytical strategy was developed by the researchers during collaborative research team meetings. Three researchers conducted independent analysis of the entire corpus of data by using NVivo 12. Findings were presented to the wider research team during regular team meetings where discrepancies were discussed and resolved and further analysis was undertaken for additional refinement.

Fairclough's three dimensions of the CDA involve the text level, discursive practice level, and social practice level. The text level is the description dimension exploring structure and content of the text. For this study, the text level involved exploring the individuals who talked, the individuals who was silent, and the use of language devices by participants. These language devices included backchannelling, which is a type of conversation feedback provided by listeners during communication, and also hedging, which involved the use of words or phrases that decreased the force of a statement. Other language devices examined were the use of humour, the use of metaphor, and the use of modality, which involved speakers judging the probability of the decisions they were making, and the use of turn-taking between individuals. These language devices were analysed according to their broad definitions, rather than using a high level of linguistic analysis. The discursive practice level comprised the interpretation dimension, which is concerned with processes of text production, consumption and distribution. These processes formed a link between the text and the social surroundings. The social practice level was the explanatory dimension that comprised how social relations influenced discursive practices (Fairclough, 1992).

The Medication Communication Model was used to analyse data in conjunction with Fairclough's CDA (Manias, 2010). The model comprised three dimensions involving antecedents, attributes and consequences of medication communication, and was useful for 
exploring the complexities surrounding medication communication. The levels of CDA were mapped against the three dimensions of the Medication Communication Model to guide data analysis. The antecedents dimension comprised sociocultural influences involving beliefs, knowledge about medications, values attached to people, social supports for managing medications, social status and power regarding conversation and environmental aspects, such as the ward culture and geographical space influencing medication communication. The antecedents dimension was aligned with the discursive practice level of CDA. The dimension related to the attributes of the actual communication encounter involved how medication communication occurred between individuals in relation to the transitions of care through exploring who was silent, who spoke, what was said, what aspects of medication care was prioritised and the use of body language and the actual words. The attributes dimension was mapped against the text level of the CDA. The consequences dimension involved evidence of the appropriate medication use, patient and family members' involvement in the medication communication and decision-making process, which was associated with the social practice level of the CDA codebook was created including all three levels of the CDA and the Medication Communication Model. Data analysis guide questions were developed from the CDA and the Medication Communication Model. These questions were developed through discussion amongst the research team, considering the aims of the research and past research examining medication communication between patients and health professionals (Manias, 2010). These questions were applied to the data during analysis. Transcripts were read several times to enable in-depth understanding of the data and facilitating data analysis. The transcripts were organised through the use of NVivo 12.

\section{Ethical Considerations}


Ethical approvals were obtained from ethics committees of the study hospital, and the university. Informed written consent was acquired from older patients, family members, nurses, pharmacists and doctors who participated in interviews, observation and focus groups. Pseudonyms were used instead of real names mentioned during interviews, focus groups or observations.

Results

Overall, 50 older patients and 31 family members participated in semi-structured interviews and 20 patients and 13 family members participated in reflexive focus groups or individual sessions following semi-structured interviews and observations. Interviews were about 30 minutes in duration while focus groups lasted approximately 20 minutes. In all, 203 hours of observation were conducted with 29 nurses, pharmacists and doctors including residents, registrars and consultants, and 111 older patients. The ages of older patients participating in the study ranged from 65 to 104 years while family members ranged from 51 to 97 years. Common reasons for admission of older patients of a musculoskeletal (34\%), respiratory $(22 \%)$, central nervous system $(12 \%)$, cardiovascular $(10 \%)$ and gastrointestinal (8\%) nature. The findings are structured under three sections including the sociocultural influences on power relations, the influences of knowledge and power relations on the actual communication encounter, and the implications of knowledge and power relations on medication safety.

\section{Sociocultural influences on the power relations}

The sociocultural influences on power relations comprised older patients using medication knowledge to advocate for themselves, and family members' advocacy for older patients. Power relations between individuals varied depending on who was in control during medication communication and decision making, how the professional status quo was 
challenged by patients during communication encounters, withholding or sharing medication knowledge, and professional authority and expertise of medication knowledge of different disciplines.

\subsection{Older patients using medication knowledge to advocate for themselves}

Patients used their knowledge about medications to take a proactive stance in making decisions, particularly at the point of discharge. Patients who had knowledge about when and how to take their regular medications voiced their concerns about their medications to health professionals during their hospital stay. Older patients who managed their own medications at home without support from family members were able to display their medication knowledge when they were admitted to the hospital. Consuming the same medications over several years instilled confidence that helped patients to clarify their concerns about how their medications should be administered following hospital admission. A 71-year-old patient who was transferred from an acute hospital to a subacute hospital explained her experience.

Staff here don't know that Creon ${ }^{\circledR}$ (pancrelipase) goes with meals and they've tried to stand over me and say 'Take it now'. No! Inappropriate! I need to digest the meals, it's immediately before or during the meal. They haven't got the message.

She expressed her frustration with the lack of consultation about the time when nurses administered her medications. Nurses' compliance with the organisational policy regarding administering the scheduled medications on time prevented them from listening to the patient's concerns.

\subsection{Advocacy for older patients by family members}

The presence of family members who knew about patients' medications helped to close the communication gap between health professionals and the patients. There were various cases 
where family members challenged medical staff by involving themselves in the medication communication process on behalf of older patients.

Family members' advocacy was important where older patients were not able to communicate about medications due to a range of intrinsic and extrinsic factors that were observed. Intrinsic factors included patient-related factors, such as being from non-English speaking backgrounds, cognitive impairment or speech problems. Extrinsic factors included organisational pressures such as the busyness of health professionals, patients being seen by multiple health professionals - such as speech pathologists, pharmacists - at the same time as nurses administering medications, visiting patients, and patients having limited access to interpreter services. In one notable observation, a daughter acted as an advocate for her mother who was from a non-English speaking background. The consultant decided to visit the 81-yearold patient who was having excruciating gut pain since he knew that her family member was present at that time and the communication could be more effectively facilitated:

Daughter: What sort of pain relief are you thinking of?

Consultant: So there's antispasmodics, means that slow down the peristalsis as I was saying. And maybe we'll try a tiny touch of morphine or something like the Targin (oxycodone \& naloxone) and see if it does anything ... but if doesn't, we might just not try it any more. Because it is usually not the solution for this type of problem.

Daughter: In emergency on Sunday, they said to me that they thought that the cramping can sometimes be caused by going off the Targin (oxycodone \& naloxone) and off the Endone (oxycodone). That's not this?

Consultant: Well, it does not help, [inaudible] this is confuse the picture, but I don't think that it is the major reason for this-

In the above conversation, the older patient was silent in medication communication due to her limited English. However, the daughter was very proactive, talking on behalf of her mother and frequently asking questions to clarify the confusion around the changes made to her mother's medications and excruciating gut pain. 


\section{Influences of knowledge and power relations on the actual communication encounter}

\subsection{Medication knowledge shared by doctors with older patients}

Doctors tended to adopt an authoritative discourse when communicating medication changes to older patients. There were many situations where older patients were not involved in discussions with senior doctors about their regular medication regimens or the rationale for changes made to these regimens. These situations often involved older patients' lack of knowledge about their own medications, difficulties in hearing, language barriers, and doctors' physical distance from patients. Doctors also tended to make changes first on the medication charts and expected other health professionals to inform patients about these changes after the event.

In an observation conducted with the registrar - a doctor who is training to become a specialist - and a medical resident - a junior medical officer - the registrar reviewed a 92-yearold patient during the ward round. The registrar tried to locate the indications for pregabalin and Nexium ${ }^{\circledR}$ (esomeprazole) prescriptions in the electronic medical record with the resident. The registrar decided to cease the pregabalin, which was commenced at the transferring hospital. The patient was informed of the medication at the end of the conversation:

Registrar to resident: What's her haemoglobin?

(The resident and student check the patient's blood results on the computer.)

Registrar to patient: Do you ever take medication for it?

Patient: [I have] medication for so many things.

Resident: $\mathrm{Hb}$ (haemoglobin) 123.

Registrar: So pred's at baseline (prednisolone) ... what's the pregabalin for?

The medical team look through the patient's medical clinical notes on the computer. 
Registrar: And also the Nexium ${ }^{\circledR}$ (esomeprazole) ... oh she had an ulcer so keep the Nexium ... but the pregabalin ... ... and what dose is she on? (says the dose-25mg) ... ok, let's stop it.

Registrar to patient: When you were at XXX (affiliated subacute hospital), the doctors started a pain medication at night ... but we're going to stop it

Registrar: [We're going to reduce it]

Registrar: Tell the nurses if you've got pain. (The medical team leaves the patient's bedside.)

The medical registrar used medical jargon (haemoglobin) when questioning about the blood test. Based on the patient's response to the doctor's specific inquiry about whether or not she took any medication for maintaining iron levels ("I have medication for so many things"), she indicated that she did not understand the question and possibly her medications.

With the recent introduction of electronic health records (EHR), doctors and nurses started to visit patients with computers on wheels, which changed the interaction styles between health professionals and patients, as well as the way in which health professionals used the space at the bedside during medical encounters. In this observation, the registrar moved to stand next to the resident at the computer, away from the bedside and looked at the patient's online medication chart to locate the information. The registrar started discussing with the resident and student quietly by looking at the computer screen rather than sharing knowledge with the older patient. The opportunities for the older patient to question the decisions made about her medications were hindered because doctors exercised power by controlling the conversation turns, and the shortness of the time disabled a patient response during conversation.

The medical registrar was in control of the communication flow, and the decisions about the changes to the medications that were initially prescribed at the previous hospital from where the patient was transferred. Since the nurse was absent in this communication, the registrar deferred responsibility to the patient to inform the nurse if she felt pain after the 
medication change. However, given that the patient was hard of hearing, the doctors did not seek her feedback to make sure that the patient had heard or understood the message.

Doctors' physical distance from bedside was one of obstacles for older patients to involve themselves into the medication communication. During an interview with a 71-yearold patient, the patient expressed that the physical distance between himself and the medical team was a barrier since he was hard of hearing:

There'll be a lot of background noise and I really find it hard to hear, so I have to get closer, I have to ask them to repeat it and if I have to ask them to repeat it twice and then I still need a third time, embarrassment would probably stop me from doing that.

\subsection{Nurses acting as delegators between doctors and patients}

Nurses acted as delegators in informing patients about medication changes at times when doctors were absent from the bedside. Nurses used an indirect style of communication aimed at older patients when they were conveying the medication changes decided by doctors and indicated that this advice was initiated by doctors. Most of the time, nurses informed patients about medication changes by doctors immediately before medication administration, which left patients no opportunity to speak up for themselves to state their agreement or disagreement with medication changes. However, considering their workload, nurses subordinated communicating about medications to the other tasks that needed to be completed in a limited time. During an interview with a 71-year-old patient, the researcher asked whether or not the nurses talked about the medications since the patient was admitted to the acute hospital. The patient stated: "Not-no, they're just lovely the nurses here. But they just come in and just do the medication. They don't get too involved in it."

In the following observation excerpt, the nurse entered the patient's room to administer the morning medications and started the conversation with an apology for being late. The 
patient initiated communication about his regular Vitamin B12 injection without any prompts by the nurse:

Nurse: Hi ... little late sorry

Patient: I forget to tell those professors ... I'm supposed to be on a Vitamin B12 injection ... every three months

Nurse: So, it's overdue?

Patient: Yeah, it's overdue

Nurse: Alright, we will ask them (doctors) to follow that up. So ... they (doctors) have now increased your Clexane ${ }^{\circledR}$ (Enoxaparin), so that little injection in your tummy to twice a day

Patient: Right

Nurse: Um so that's for the irregular heart rate, so no clots are going to cause you any problems, yeah?

Patient: Yeah ... I take it morning and night

The older patient voiced his concern about his overdue medication since he knew about the relationship between his anaemia and Vitamin B12 deficiency. He used assertive language to express the importance of his concern ("It's very important because it's got a lot to do with anaemia"). The nurse was aware that she was late with the immediate medication task and she minimised the patient's concern about the overdue medication and prioritised administering the anticoagulant injection by reassuring that she would relay his concern to the doctors. In this communication, the nurse talked on behalf of doctors and conveyed the doctor's decision about the change of enoxaparin (an anticoagulant agent) dosage to the patient just before administering the injection.

\subsection{Prioritisation of medication safety by pharmacists}

Pharmacists prioritised the discourse of medication safety when they communicated with the patients about medications, particularly at the point of discharge. At discharge, pharmacists attempted to involve older patients to clarify their understanding. The following 
excerpt exemplifies the use of low modality language employed by a pharmacist when she was explaining the rationale why atorvastatin was ceased:

Atorvastatin was a tablet we use for our cholesterol. Around probably in this age and time, we probably won't need it necessarily. So the reason why we stopped it, because the livers were acting up a bit. And normally when you take this medication, sometimes it can maybe increase it, or maybe something else happened that caused the liver enzymes to increase.

Pharmacists used low modality language and hedging to be less assertive as demonstrated by the bolded text, whereas patients tended to use the discourse of politeness in a mitigated manner while expressing their concerns. In this instance, the pharmacist used frequent low modality words such as probably, sometimes and maybe while explaining the rationale for stopping atorvastatin. She also used the phrase maybe because of the pharmacist's lack of ownership about the decision made about atorvastatin.

During an observation, the pharmacist wanted to visit the patient who was just admitted to a rehabilitation ward to discuss about Plavix ${ }^{\circledR}$ (clopidogrel) since she had some concerns about why doctors in the hospital stopped her regular medication. The patient was very concerned, because she previously had two cardiac stents and took Plavix ${ }^{\circledR}$ regularly:

Patient: You want to see my pills, right?

Pharmacist: My name is (Tells her name), I am the pharmacist.

Patient: OK, well I'll show you my pill regime. It is normal.

Pharmacist: Ok, great.

Patient: Let me find it.

Pharmacist sees the dark chocolate on the table: Does it include dark chocolate and jam?

Patient: Of course, it does! (laughs)

Pharmacist: (laughs) A spoonful of sugar helps the medicine go down.

Patient: Of course! Don't hear that very often believe me. That's- 


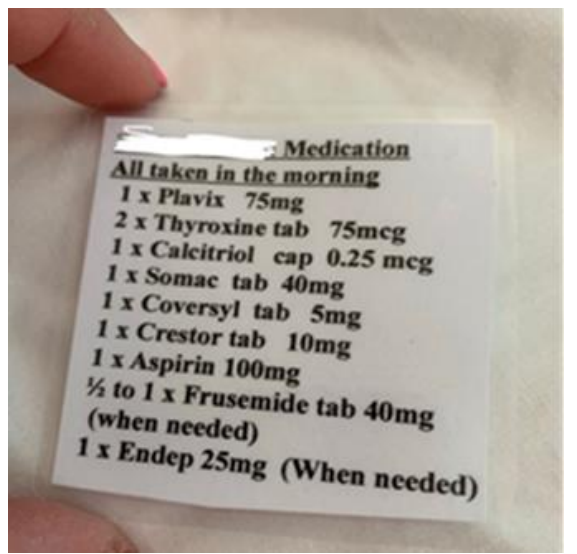

(Patient gives her little laminated medication list to the pharmacist and pharmacist very likes it.)

Pharmacist: Ooh! That's nice.

Patient: ... Now my Plavix ${ }^{\circledR}$ has been stopped.

Pharmacist: Do you know why?

Patient: Well, because of the operation it had to stop to start with. But I would prefer to go back on the Plavix ${ }^{\circledR}$ (clopidogrel) and stop the aspirin.

Pharmacist: Ok.

Patient: Because the Plavix ${ }^{\circledR}$ is there specifically for my stents.

\section{Pharmacist: Yes.}

Patient: So, I would prefer to switch over.

Pharmacist: So, this.. so when were your stents put in?

Patient: In 2009 and I've had several angiograms since. Checking them all out and what have you and they are fine. I have got a clearance from my cardiologist before I came down for this operation. Everything was fine.

Pharmacist: So the team (Cardiology team) spoke to our doctors but you have your own specialist, so I might ask our team to give yours a call. And um...you are right, that it was stopped for the surgery. And then there was a discussion around because your stents were in 2009 do you still need to be on two antiplatelets.

Patient: Yes, that was why they said they weren't going to put it back on.

Pharmacist: Yep. Our cardiology team said that it would be fine to stop the clopidogrel and just continue with aspirin.

Patient: Oh, ok.

Pharmacist: So, they're both antiplatelets. Ahm, first line generally speaking is aspirin.

Patient: Yes. (Conversation continued and took 32 minutes in total.)

The patient had laminated her medication list on a small piece of paper including her name, and medications with their dosages and frequencies. She used this list as a communication aid when talking to the pharmacist about her regular medications. In addition, the patient initiated the conversation as soon as the pharmacist entered the patient's room. The pharmacist was standing at the bedside and making constant eye contact with the patient who 
was sitting on the bed. The pharmacist's use of humour at the beginning of the conversation built rapport with the patient. The patient took the initiative to show her medications and pointed out Plavix ${ }^{\circledR}$ in her small medication list by questioning the reason why it was stopped by the hospital medical team. The patient believed that Plavix ${ }^{\circledR}$ (clopidogrel) was more important than aspirin. By using a politeness strategy with less assertive language and low modality words ("I would prefer to go back on the Plavix ${ }^{\circledR}$ (clopidogrel) and stop the aspirin" and "I would prefer to switch over"), the patient mitigated her resistance to the dominant decision made by the cardiology team at the hospital. The pharmacist spoke on behalf of the cardiology team and informed the patient about the rationale behind the medication change. However, it was obvious that the pharmacist stood by the authority of the cardiology team as key decision makers in contrast to the resistance posed by the patient. She was trying to convince the patient about not needing two antiplatelet medications, making reference to the time when the patient's stents were put in. A turn-taking sequence was exercised in a cooperative and smooth manner without any overlapping conversation and both sides used polite language. It helped to reduce asymmetrical power relations between the pharmacist and the patient where the pharmacist exercised the authority to support the therapeutic decision made by doctors.

\subsection{Challenge of unequal power relations by family members}

The presence of family members was important in challenging the asymmetric power arising from traditional patient-health care provider relationships. Communication between patients and health professionals was sometimes difficult where older patients were not able to contribute equally to the interaction due to their hearing issues, speech problems, language barriers or cognitive barriers. Observations with health professionals demonstrated that family members obtained specific information about particular medications and also questioned the 
rationale behind medication changes. There were also times where family members displayed their experiential knowledge of older patients' illness and their medication management at home. The following interaction occurred between the pharmacist and a patient's wife waiting in the corridor. The patient was not able to communicate clearly due to his speech problem and he was examined by the speech pathologist. The pharmacist opportunistically approached the patient's wife with the possibility of reconciling the patient's medications:

Wife: He has gout. We wait if it will develop again. I mean it is extremely painful. He got Plantar fasciitis as well, not that you can do much about that. They put a cortisone into it. But, yeah. Somebody who's got such a little ability to walk, any little thing will be three times as much ... So I try to attend to everything, what you can.

Pharmacist: I know. That's OK, you are doing a great job (the name of wife), thank you very much for your time. I really appreciate-

Wife: -That's all right. I hope I was-

Pharmacist: No, you were very helpful. Ahm, what I'll do is, I'll pop by and say hello to (the name of the patient) myself. But if you can just let him know, that if he has any questions at all about medicines at all, he can ask me, or even say hello.

Wife: I don't know if you want to talk to him, they measure his sugar and he says "Ahh! That's too high". (Laughs) He is really impossible.

Pharmacist: (Laughs) That's ok. (Communication continues...)

During communication between the patient's wife and the pharmacist were standing and the pharmacist was constantly making eye contact with the wife, she was nodding to express that she was following her. The wife wanted to raise the topic of the patient's insulin management at home by using the discourse of politeness ("I don't know if you want to talk to him...."). The wife also used humour ("He is really impossible") when she was describing her husband's attitude towards insulin management. In that way, the wife attempted to convey that the pharmacist needed to educate the patient about his insulin dosages during the bedside consultation. The patient believed that his blood sugar should be lower than what the endocrinologist suggested, which led him to take more insulin than prescribed at home. 
Eventually, the pharmacist discussed the patient's insulin regimen in a slow manner considering his speech problem. The wife prompted the pharmacist to educate the patient about his regular insulin regimen since the patient had overdosed at home, which caused lifethreatening hypoglycaemia. The pharmacist's bedside consultation with the patient about insulin dosages was important to prevent possible insulin mismanagement after discharge.

In another observation, the consultant visited a 65-year-old patient with the registrar during the ward round. The patient's brother immediately entered the room and became involved in the conversation. The brother's entrance changed the content and flow of the bedside interaction. The brother used an interrogative voice tone, asking doctors to provide further clarification for an abbreviation that they used to explain the patient's medication treatment:

Patient's brother enters room, immediately asks question regarding the patient: So, what is happening with her today? ... What's going on today?

The consultant: We are hoping she is going to continue to improve. She is getting a bit more IVIG (Intravenous Immunoglobulin).

The brother: What's that in English?

The patient: That's that ...

The registrar: The infusion ...

The brother: Oh ok.

The less senior doctor: So today's the last day of that. It's day 5.

The brother: What happens after that?

The patient: Wait and see.

3. Consequences of the actual communication encounter-Implications of power-

\section{knowledge relations on the medication safety}

The outcomes of the actual communication encounter involved two major consequences. These were prevention of potential and actual medication incidents upon patients' admission to the hospital or after discharge, and participation of older patients in decision making about medications. 


\subsection{Preventing potential and actual medication incidents}

Medication incidents can be reduced across transitions of care if older patients were well-informed about their medications in order to be actively involved in medication communication with health professionals. Some older patients challenged health professionals by voicing their concerns about the medications that were missed after they were admitted to the hospital. There were times when older patients felt their medication allergies were not extensively checked with them before medications were administered by nurses at the bedside. Instead, nurses often gave precedence to complying with organisational discourses by completing medication administration tasks in a timely manner rather than engaging with older patients in discussing about their medication concerns. In contrast, when pharmacists implemented a discourse of cooperation during medication communication, older patients felt they took responsibility in solving issues caused by medication discrepancies across settings. For instance, older patients sometimes prompted pharmacists to contact other health professionals situated in community settings or previous hospitals from where they were transferred, to clarify the medications that were missed when patient moved between settings.

A medication incident was captured during an observation of a pharmacist when she was going through medications with an 88-year-old patient at the bedside. The patient realised that his eye drops had not been administered for days. The patient had cataract surgery at a different hospital six weeks ago. The patient's post-procedure eye care regimen was not charted by doctors upon transfer to the hospital setting from the aged care facility where the patient lived. Having realised that he had missed his medication following his eye surgery, the patient voiced his concerns to the pharmacist. The pharmacist confirmed that she would ask the doctors to chart the missed medication. 
Older patients' knowledge of medication allergies helped them to question nurses' professional control over the medication administration process when they were admitted to the hospital. This knowledge prevented them from experiencing medication incidents. An 83year-old patient's understanding about her aspirin allergy prevented her from taking it at the last minute:

It was like last night they were going to give me aspirin. Well I've been allergic to aspirin for 50 years and it's written on my record, so whoever, they made a mistake because it's been written on my records here for, well ever since I've been coming here. Well, I always ask if any new thing is been given to me and luckily I said, "I'm allergic," so I didn't take it.

\subsection{Participation in medication communication}

Where there were frequent attempts from health professionals throughout their interaction to invite older patients to discuss their medications, older patients tended to take a more active role in demonstrating their medication concerns. Some older patients involved themselves in informal conversations with pharmacists and nurses at the bedside where nurses and pharmacists used a partnership discourse to explain medication changes across transitions. However, medication information exchange between older patients and health professionals rarely occurred during ward rounds, which tended to be the domain of doctors.

Pharmacists were more likely to use medication practices in innovative ways, which increased patients' participation. They counselled about discharge medications by pointing out information on the discharge medication list and also showing the medication boxes at the same time to activate the patient's visual memory. They sometimes showed labels to indicate the generic names of medications if the hospital supplied different brands of a specific medication that older patients used to take at home. Shared-decision making was more likely to happen when health professionals used a discourse of cooperation during medication communication 
by asking the patients' opinion rather than just letting patients know about the final decisions that they made about medications. A 71-year-old patient expressed that she felt involved with the decision made about her analgesic when she was first transferred to the subacute hospital from the acute hospital: “They (doctors) didn't just come in and say, “We're cutting it by 25 \%.". They came in and said, "We're thinking of cutting it by $25 \%$. How do you feel?" and that worked really well."

\section{Discussion}

Older patients' knowledge about their medications and the advocacy role of family members were helpful in challenging inherent power relations between patients and health professionals across transitions. Older patients who were silent during communication encounters contributed to maintaining the status quo where doctors were in the position of deciding what information they could share or withhold about medications during communication encounters. In contrast, pharmacists attempted to equalise power imbalances by sharing more detailed information with patients about their medications changes across settings and also encouraged older patients to provide more input into medication decisions. Older patients' active participation in communicating about medications prevented medication discrepancies across transitions of care.

The presence of authoritative discourse was displayed when senior doctors led the communication and controlled the knowledge shared about medications with patients. During encounters with doctors conducting ward rounds, older patients were less likely to be involved in discussions about medications that were stopped or started at a transferring hospital. Their lack of involvement in these discussions with doctors may have been due to older patients' perceptions of their limited knowledge about their regular medications or their belief that doctors knew better about making appropriate medication decisions. Similarly, Belcher et al. 
(2006) found older patients reported their perceived lack of medication knowledge led to their exclusion from medication decision-making.

Having different levels of control in how knowledge was consumed, produced, and distributed created social impacts on maintaining unequal asymmetries amongst patients and health professionals. In this study, knowledge about specific medications prescribed in previous settings was easily accessible to doctors by access to electronic medical records during bedside visits, where this written knowledge was not visible to older patients. This lack of visibility may have resulted in unequal consumption and distribution of written medication knowledge between doctors and patients. Therefore, it appeared that doctors held institutional power in dominating the decision-making process. Whilst computerised systems helped doctors to view medication information across patients' care transitions, these systems impeded older patients from being invited on medication discussions with doctors during ward rounds.

Relationships between older patients and health professionals influenced older patients' involvement in medication decisions from admission to discharge. Following patients' admission to the hospital, doctors tended to make various changes to patients' regular medications or medications prescribed in previous settings. Our findings support earlier work, which found that doctors tended to make these medication decisions away from the bedside without eliciting patients' opinions, particularly where patients were hard of hearing or too sick to be involved in communication upon their admission to the hospital setting (Liu et al., 2016). Nevertheless, there were times during the hospital stay where older patients indirectly hinted at their resistance to dominant decisions made by doctors to the bedside nurse or the ward pharmacist by using the discourse of politeness. However, the findings revealed that nurses were inclined to prioritise the completion of tasks over the investigation of patients' medication concerns in order to maintain organisational efficiency, which has also been identified in the literature (Bolster \& Manias, 2010; Manias et al., 2005). 
The pharmacists' role in communicating medication information to older patients and family members across transitions of care was substantial. Particularly at discharge, pharmacists took up the discourse of medication safety by using diverse communication strategies such as showing patients their written summaries and medication boxes to encourage older patients' engagement with medication education. Our findings support earlier work, which found that pharmacists aimed to enhance patients' control during communication by asking for their ideas and opinions about the medications (Shah \& Chewning, 2006). Although pharmacists attempted to give more control to older patients by prompting them with frequent questions, some older patients reported that they felt exhausted by the amount of information provided at discharge meetings. This finding can be explained by time pressures and the stressful nature of hospital environments, leading to information overload during the provision of pharmacists' discharge education (Manias et al., 2015).

There are many implications arising from this study. To reduce unequal power relations, health professionals need to be more proactive in sharing information about medications with older patients during communication encounters. Health professionals could adopt strategies and tools aimed at improving medication communication with older patients and family members. For instance, electronic information about medications can be made available by bedside tablets or applications for older patients or their family members as they move to a new environment between or within hospitals, so that they can visually access the most updated information before or during actual communication encounters. Further, nurses should refocus on activities that are more patient focused such as checking patients' experiences with medications, including allergies, and wanted and unwanted effects with medications, rather than merely aiming to have medication administration completed within a designated time. Health professionals could assess older patients' knowledge about their medications and recognise teachable moments across their hospital stay. In this study, doctors 
and nurses seemed to rely on pharmacists to communicate about medication with older patients before discharge. However, increasing older patients' medication knowledge requires collaboration amongst doctors, pharmacists and nurses throughout an older patient's journey across transitions of care. Medication administration processes can be used as an opportunity for nurses to assess older patients' knowledge about their medications, and to provide required information that older patients need. Discussing medications with older patients just before discharge may not be enough for them to retain the knowledge of the various changes, which happened to their regular medications. These discussions about planning for discharge should occur regularly during older patients' hospitalisation. Plain written information highlighting medication changes as older patients move across transitions of care should be made available for older patients and family members to assist with their learning.

The main limitation of this study is that participants may have demonstrated awareness as a result of being observed by researchers. However, observations were conducted over extended hours, which helped the researchers to gain trust and alleviate any feelings of discomfort caused from being observed. The study may not be applicable to hospitals located within regional or rural areas or to hospitals located in various countries because of differences in health care systems. Older patients with severe cognitive impairment were not included in the study and hence the results cannot be applied to this patient group.

\section{Conclusions}

Older patients' knowledge about managing their regular medication regimens encouraged them to articulate their concerns during communication encounters. Doctors were inclined to assume an authoritative discourse when explaining medication decisions or changes occurred across transitions. Nurses played a delegator role in transferring medication knowledge between older patients and doctors, and they tended to subordinate communicating 
with patients about their medication concerns in concentrating on other tasks they needed to complete on time. Pharmacists prioritised the discourse of medication safety when they communicated with the older patients, especially before discharge.

\section{Declaration of Conflicting Interests}

The authors declared no potential conflicts of interest with respect to the research, authorship, and/or publication of this article.

\section{Funding}

This research is funded by an Australian Research Council, Discovery Project Grant (DP170100308). 
Allen, J., Hutchinson, A. M., Brown, R., \& Livingston, P. M. (2016). User Experience and Care Integration in Transitional Care for Older People From Hospital to Home: A Meta-Synthesis. Qualitative Health Research, 27(1), 24-36 https://doi.org10.1177/1049732316658267

Australian Commission on Safety and Quality in Health Care. (2015). Engaging Patients in Communication at Transitions. Sydney: ACSQHC: Prepared by a consortium from Deakin and Griffith Universities.

Bagge, M., Norris, P., Heydon, S., \& Tordoff, J. (2014). Older people's experiences of medicine changes on leaving hospital. Research in Social and Administrative Pharmacy, 10(5), 791-800 https://doi.org10.1016/j.sapharm.2013.10.005

Belcher, V. N., Fried, T. R., Agostini, J. V., \& Tinetti, M. E. (2006). Views of older adults on patient participation in medication-related decision making. Journal of General Internal Medicine, 21(4), 298-303 https://doi.org10.1111/j.1525-1497.2006.00329.x

Bolster, D., \& Manias, E. (2010). Person-centred interactions between nurses and patients during medication activities in an acute hospital setting: Qualitative observation and interview study. International Journal of Nursing Studies, 47(2), 154-165 https://doi.org10.1016/j.ijnurstu.2009.05.021

Braun, V., \& Clarke, V. (2006). Using thematic analysis in psychology. Qualitative Research in Psychology, 3(2), 77-101 https://doi.org10.1191/1478088706qp063oa

Bucknall, T., Digby, R., Fossum, M., Hutchinson, A. M., Considine, J., Dunning, T., et al. (2019). Exploring patient preferences for involvement in medication management in hospitals. Journal of Advanced Nursing, 75(10), 2189-2199 https://doi.org10.1111/jan.14087

Burbach, B., Cohen, M., Zimmerman, L., Schmaderer, M., Struwe, L., \& Paulman, A. (2016). Post-hospitalization transition to home: Patient perspectives of a personalized approach. Journal of Nursing Education and Practice, 6 https://doi.org10.5430/jnep.v6n5p32

Byrne, K., Orange, J. B., \& Ward-Griffin, C. (2011). Care Transition Experiences of Spousal Caregivers: From a Geriatric Rehabilitation Unit to Home. Qualitative Health Research, 21(10), 1371-1387 https://doi.org10.1177/1049732311407078

Chiu, P. K., Lee, A. W., See, T. Y., \& Chan, F. H. (2018). Outcomes of a pharmacist-led medication review programme for hospitalised elderly patients. Hong Kong Med J, 24(2), 98-106 https://doi.org10.12809/hkmj176871

Clyne, B., Cooper, J. A., Boland, F., Hughes, C. M., Fahey, T., \& Smith, S. M. (2017). Beliefs about prescribed medication among older patients with polypharmacy: A mixed methods study in primary care. British Journal of General Practice, 67(660), 507-518 https://doi.org10.3399/bjgp17X691073

Coleman, E. A. (2003). Falling Through the Cracks: Challenges and Opportunities for Improving Transitional Care for Persons with Continuous Complex Care Needs. Journal of the American Geriatrics Society, 51(4), 549-555 https://doi.org10.1046/j.1532-5415.2003.51185.x

Fairclough, N. (1989). Language and power. London: Longman.

Fairclough, N. (1992). Discourse and social change. London; New York: Polity Press.

Knoblauch, H. (2005). Focused Ethnography. Forum: Qualitative Social Research, 6(3), 1-14 
Kramlich, D., Kronk, R., Colbert, A., Jakub, K., \& Marcellus, L. (2018). Rural postpartum women with substance use disorders. Qualitative Health Research, 28(9), 1449-1461 https://doi.org10.1177/1049732318765720

Liu, W., Gerdtz, M., \& Manias, E. (2016). Creating opportunities for interdisciplinary collaboration and patient-centred care: How nurses, doctors, pharmacists and patients use communication strategies when managing medications in an acute hospital setting. Journal of Clinical Nursing, 25(19-20), 2943-2958

Liu, W., Manias, E., \& Gerdtz, M. (2014). Medication communication through documentation in medical wards: knowledge and power relations. https://doi.org10.1111/nin.12043

Macdonald, M. T., Heilemann, M. V., Mackinnon, N. J., Lang, A., Gregory, D., Gurnham, M. E., et al. (2014). Confirming delivery: Understanding the role of the hospitalized patient in medication administration safety. Qualitative Health Research, 24(4), 536550 https://doi.org10.1177/1049732314524487

Manias, E. (2010). Medication communication: A concept analysis. Journal of Advanced Nursing, 66(4), 933-943 https://doi.org10.1111/j.1365-2648.2009.05225.x

Manias, E., Aitken, R., \& Dunning, T. (2005). How graduate nurses use protocols to manage patients` medications. Journal of Clinical Nursing, 14(8), 935-944 https://doi.org10.1111/j.1365-2702.2005.01234.x

Manias, E., Gerdtz, M., Williams, A., McGuiness, J., \& Dooley, M. (2016). Communicating about the management of medications as patients move across transition points of care: An observation and interview study. Journal of Evaluation in Clinical Practice, 22(5), 635-643 https://doi.org10.1111/jep.12507

Manias, E., Rixon, S., Williams, A., Liew, D., \& Braaf, S. (2015). Barriers and enablers affecting patient engagement in managing medications within specialty hospital settings. Health Expectations, 18(6), 2787-2798 https://doi.org10.1111/hex.12255

Mesteig, M., Helbostad, J. L., Sletvold, O., Rosstad, T., \& Saltvedt, I. (2010). Unwanted incidents during transition of geriatric patients from hospital to home: A prospective observational study. BMC Health Services Research, 10, 1-9 https://doi.org10.1186/1472-6963-10-1

Modig, S., Kristensson, J., Troein, M., Brorsson, A., \& Midlöv, P. (2012). Frail elderly patients' experiences of information on medication: A qualitative study. BMC Geriatr, 12(1), 46 https://doi.org10.1186/1471-2318-12-46

Moen, J., Bohm, A., Tillenius, T., Ring, L., Antonov, K., \& Nilsson, J. L. G. (2009). "I don't know how many of these [medicines] are necessary.."-A focus group study among elderly users of multiple medicines. Patient Education and Counseling, 74(2), 135141 https://doi.org10.1016/j.pec.2008.08.019

Ozavci, G., Bucknall, T., Woodward-Kron, R., Hughes, C., Jorm, C., Joseph, K., et al. (2020). A systematic review of older patients' experiences and perceptions of communication about managing medication across transitions of care. Journal of Research in Social and Administrative Pharmacy, 1-19 https://doi.org10.1016/j.sapharm.2020.03.023

Rashidian, A., Eccles, M. P., \& Russell, I. (2008). Falling on stony ground? A qualitative study of implementation of clinical guidelines' prescribing recommendations in primary care. Health Policy, 85(2), 148-161 https://doi.orghttps://doi.org/10.1016/j.healthpol.2007.07.011 
Shah, B., \& Chewning, B. (2006). Conceptualizing and measuring pharmacist-patient communication: A review of published studies. Research in Social and Administrative Pharmacy, 2(2), 153-185 https://doi.org10.1016/j.sapharm.2006.05.001

Shen, Q., Karr, M., Ko, A., Chan, D. K., Khan, R., \& Duvall, D. (2006). Evaluation of a medication education program for elderly hospital in-patients. Geriatr Nurs, 27(3), 184-192 https://doi.org10.1016/j.gerinurse.2006.03.015

Spinewine, A., Tulkens, P. M., Swine, C., Dhillon, S., Franklin, B. D., Wilmotte, L., et al. (2005). Appropriateness of use of medicines in elderly inpatients: Qualitative study. British Medical Journal, 331(7522), 935-938 https://doi.org10.1136/bmj.38551.410012.06

Stange, D., Kriston, L., von-Wolff, A., Baehr, M., \& Dartsch, D. C. (2013). Reducing cardiovascular medication complexity in a German university hospital: Effects of a structured pharmaceutical management intervention on adherence. J Manag Care Pharm, 19(5), 396-407 https://doi.org10.18553/jmcp.2013.19.5.396

Surbhi, S., Munshi, K. D., Bell, P. C., \& Bailey, J. E. (2016). Drug therapy problems and medication discrepancies during care transitions in super-utilizers. Journal of the American Pharmacists Association, 56(6), 633-642 https://doi.org10.1016/j.japh.2016.07.004

Toubøl, A., Moestrup, L., Nielsen, D. S., Ryg, J., \& Thomsen, K. (2020). "Even though I have dementia, I prefer that they are personable": A qualitative focused ethnography study in a danish general hospital setting. Global Qualitative Nursing Research, 7 https://doi.org10.1177/2333393619899388

Wong, C., \& Hogan, D. B. (2016). Care transitions: Using narratives to assess continuity of care provided to older patients after hospital discharge. Canadian Geriatrics Journal, 19(3), 97-102 https://doi.org10.5770/cgj.19.229

World Health Organization. (2016). Transitions of care: Technical series on safer primary care. Geneva: WHO. 